\title{
Microbial diversity and ecotoxicity of sediments 3 years after the Jiaozhou Bay oil spill
}

\author{
Wei Gao ${ }^{1,2 \dagger}$, Xiaofei Yinn ${ }^{2 \dagger}$, Tiezhu Mi ${ }^{3,4,5}$, Yiran Zhang ${ }^{2}$, Faxiang Lin², Bin Han², Xilong Zhao², Xiao Luan², \\ Zhisong Cui ${ }^{2}$ and Li Zheng ${ }^{2,5^{*}}$
}

\begin{abstract}
In 2013, the "Qingdao oil pipeline explosion" released an estimated 2000 tons of oil into the environment. Sediment samples were collected from ten sites in Jiaozhou Bay and Shilaoren Beach to evaluate the influence of the spilled oil on the benthic environment 3 years after the oil spill accident. The compositions of oil, bacterial diversity and biotoxicity were examined in this study. The results showed that the concentration of total petroleum hydrocarbons (TPHs) peaked near the oil leak point and gradually decreased along the coastline, ranging from 21.5 to $133.2 \mu \mathrm{g} / \mathrm{g}$. The distribution of polycyclic aromatic hydrocarbons (PAHs) was correlated with TPH, and naphthalenes were dominant in the 20 detected PAHs. The bacterial diversities in seriously polluted and slightly polluted sediments were completely different. As degrading bacteria, Alcanivorax and Lutibacter were the main genera at the oil-polluted sites. The analysis of biotoxicity by the luminescent bacteria method showed great differences among the polluted sites, the control site in Jiaozhou Bay, and the non-polluted site outside of Jiaozhou Bay. The biotoxicity also peaked at the site near the oil leak point. These results indicate that the oil spill that occurred 3 years ago still affects the environment and impacts the bacterial communities in the sediments.
\end{abstract}

Keywords: Oil spill, Petroleum hydrocarbons, Sediment, Bacterial diversity, Biotoxicity

\section{Introduction}

On Nov 22nd, 2013, an oil pipeline exploded in Huang Dao, Qingdao City, China. The crude oil spilled into the sea through the municipal pipelines. An estimated $2.5 \mathrm{~km}$ of shoreline was seriously polluted by the oil spill. To mitigate the impact of the oil, dispersants were applied to surface waters around the leak point. The use of the dispersants was meant to promote the deposition of the oil to the sea floor (Gong et al. 2014). Meanwhile, the harbour (near the leak point in Jiaozhou Bay-an inner sea) might prevent the oil from reaching the open sea. The special hydrological characteristics of these sites might

\footnotetext{
*Correspondence: zhengli@fio.org.cn

tWei Gao and Xiaofei Yin contributed equally to this work

${ }^{2}$ Key Laboratory for Marine Bioactive Substances and Modern Analytical

Technology, The First Institute of Oceanography, State Oceanic

Administration of China, No. 6 Xianxialing Road, Qingdao 266000,

Shandong, People's Republic of China

Full list of author information is available at the end of the article
}

keep the oil near the shoreline where it could persist for a long time. Therefore, the spilled oil would have a different impact on the benthic environment.

Major concerns were raised about the long-term influence of the spilled oil on the marine environment (Hong et al. 2012; Peterson et al. 2003; White et al. 2014). To assess the ecological impact of the spilled oil, it was important to know the full extent and level of contamination at impacted locations as well as how the oil spill impacted the bacterial community. The responses of bacterial communities to oil spills have frequently been studied, especially in Mexico after the Deepwater Horizon oil spill (Acosta-González et al. 2013; King et al. 2015). Recently, studies began focusing on the long-term impacts of the Deepwater Horizon oil spill on the environment (Yergeau et al. 2015; Beyer et al. 2016; Romero et al. 2017). In this study, we sampled the polluted sediments, identified the diversity of the bacterial community and tested the biotoxicity of the polluted sediments. 
The samples from the non-contaminated areas served as controls to distinguish the oil spill signature from the background hydrocarbons. This research provides basic information on the long-term influence of oil contamination on the benthic environment.

\section{Materials and methods}

\section{Sampling and experimental design}

Sediments were collected using a bottom sampler. We selected three sampling sections (i.e., A, B, and C) parallel to the shoreline. The sampling sites were designated based on the line name and number, e.g., B1, B2 and B3 were the sites in line $\mathrm{B}$. The three sites that were perpendicular to the shoreline of the contaminated site were named A3, B3, and C3. In total, there were ten sites in this study. Eight sites were placed around the leak point. Two sites named as MED and SLR were chosen as control sites on the other side of Jiaozhou Bay and Shilaoren Beach (Fig. 1). The collected samples were wrapped in tinfoil and persevered at $4{ }^{\circ} \mathrm{C}$.

\section{DNA extraction and sequencing}

\section{Extraction of genomic DNA from sediment samples}

Total genomic DNA was extracted from samples using the CTAB/SDS method (Rochelle 2001). DNA concentration and purity were monitored on $1 \%$ agarose gels. According to the concentration, sterile water was used to dilute the DNA to $1 \mathrm{ng} / \mu \mathrm{L}$. Prepared DNA samples were sent to Novegene (Beijing, China). The five sites were chosen for the microbial community analysis and included the three seriously polluted sites (i.e., A3, B3, C3) and the two control sites (i.e., MED and SLR).

\section{Amplification and 165 rRNA gene sequencing}

The V3-V4 regions were amplified using Phusion ${ }^{\circledR}$ HighFidelity PCR Master Mix (New England Biolabs). After purification with the Qiagen gel extraction kit (Qiagen, Germany), sequencing libraries were generated using the TruSeq ${ }^{\circledR}$ DNA PCR-Free sample preparation kit (Illumina, USA) following the manufacturer's recommendations; finally, the library was sequenced on an Illumina HiSeq2500 platform and 250 bp paired-end reads were generated. All the sequence data were submitted to the GenBank Sequence Read Archive under BioProject accession number PRJNA399274.

\section{Data analysis}

Paired-end reads were merged using FLASH (V1.2.7) to splice overlapping sequences to raw tags (Magoč and Salzberg 2011). The raw tags were performed under specific filtering conditions to obtain the high-quality clean tags according to the QIIME (V1.7.0) quality controlled process (Caporaso et al. 2010; Bokulich et al. 2013). The effective tags were finally obtained after chimera

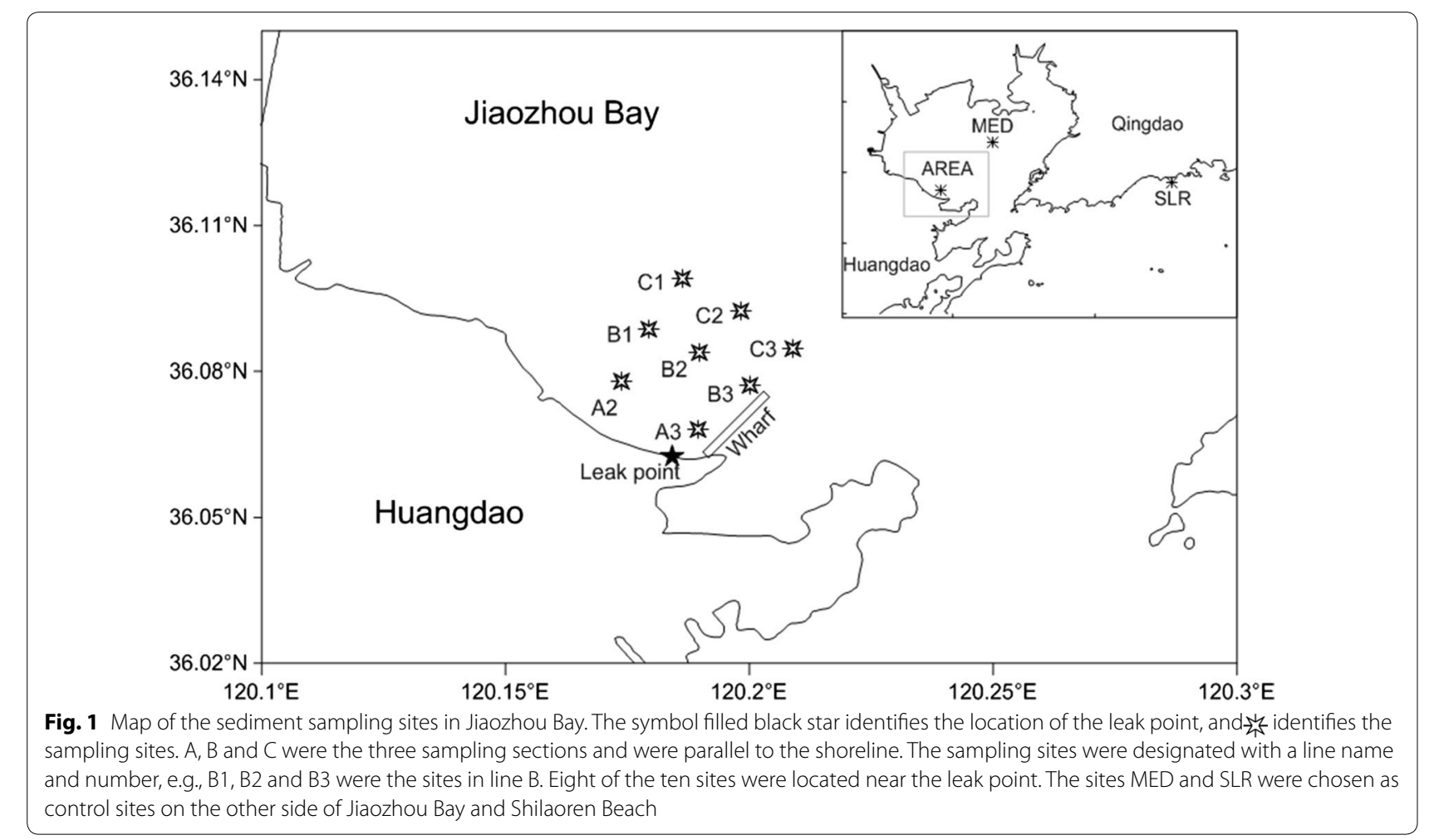


removal (Edgar et al. 2011; Haas et al. 2011). Analyses of the sequences were performed using Uparse software (Uparse v7.0.1001) (Edgar 2013). Sequences with $\geq 97 \%$ similarity were assigned to the same OTUs. A representative sequence for each OTU was screened for further annotation with the Green Gene Database (DeSantis et al. 2006) based on RDP3 classifier (Version 2.2) (Wang et al. 2007) algorithm to annotate taxonomic information. To study phylogenetic relationships of different OTUs, and the differences in the dominant species present in the different samples (i.e., groups), multiple sequences alignments were conducted using the MUSCLE software (Version 3.8.31) (Edgar 2004). Subsequent analyses of alpha diversity and beta diversity were all performed based on this normalised data output. Six diversity indices, including observed-species, Chao1, Shannon, Simpson, ACE, and good-coverage, were applied in analysing the complexity of species diversity for each sample. Principal component analysis (PCA) was preceded by the FactoMineR package and ggplot2 package in R software (Version 2.15.3).

\section{Oil concentration and composition analysis}

The sediments were freeze-dried (Christ alpha 1-4LD, Germany) before the oil analysis and $20 \mathrm{~g}$ of sediment samples were extracted with a mixture of $n$-hexane and dichloromethane. The total petroleum hydrocarbons were determined by the fluorescence spectrophotometry method according to Massoud et al. (1996) with a minor modification. The alkanes and PAHs were detected using GC-MS in triplicate using the procedures described previously (Gao et al. 2015). A 1-mL sample of the sediment extraction was dehydrated in a column with $2 \mathrm{~g}$ of anhydrous $\mathrm{Na}_{2} \mathrm{SO}_{4}$ and filtered using $0.22-\mu \mathrm{m}$ nylon membrane (JINTENG, Tianjin, China). After evaporation under a stream of nitrogen, the residual was re-dissolved in chromatography-grade $n$-hexane. $N$-tetracosaneD50 and $P$-terphenyl-D14 were set as internal standards $(10 \mu \mathrm{g} / \mathrm{mL}$ each). The samples were analysed by a 6890A gas chromatograph (Agilent Technologies) in an HP-5 MS capillary column $(30 \mathrm{~m} \times 250 \mu \mathrm{m}$ i.d., $0.22 \mu \mathrm{m}$ thickness) and a 5973 mass spectrometer equipped with a quadrupole axis detector. The semi-quantification of hydrocarbons was conducted following the protocols described by Zheng (2012).

\section{Biotoxicity test by luminous bacteria}

The biotoxicity of each sample was determined by the luminescent bacteria Acinetobacter baylyi HesenATox (Shanghai HeSen Biotechnology co., Ltd). $\mathrm{HgCl}_{2}$ was used as a reference standard toxicant with concentrations from $0.06,0.08,0.10,0.12$, and $0.14 \mathrm{mg} / \mathrm{L}$. The bacteria were prepared according to the manufacturer's instructions. The sediments were freeze-dried, and the biotoxicity was detected following the method of $\mathrm{Xu}$ (2016). The luminescence intensity was measured using a microplate reader (VictorX PerkinElmer). The toxicity analysis was conducted similar to Luan (2015). The luminous inhibition rate was calculated using the following formula.

$$
\mathrm{IHR}=\left(\mathrm{L}_{\mathrm{CK}}-\mathrm{Ls}\right) / \mathrm{L}_{\mathrm{CK}} \times 100 \%
$$

$\mathrm{L}_{\mathrm{CK}}$ is the luminous intensity of the negative control and Ls is the luminous intensity of the sample or positive control $\left(\mathrm{HgCl}_{2}\right)$. The linear regression equation was established with the IHR and the corresponding concentration of mercury chloride. The equivalent concentration of the sample was calculated using this regression equation, and the toxicity evaluation referred to Luan's grading method.

\section{Results}

\section{Determination of total petroleum hydrocarbons} by fluorescence spectrometry

The total petroleum hydrocarbons were quantified in this research by fluorescence spectrophotometry. Sediments from ten sites were collected; these included eight sites near the site of the oil spill (i.e., samples A2-C3) and two control sites in Jiaozhou Bay and Shilaoren Beach. The $\mathrm{TPH}$ concentrations ranged from 21.5 to $133.17 \mu \mathrm{g} / \mathrm{g}$. No TPH concentration was detected at the control site SLR. The highest TPH concentration was in the sample from site A3. The concentrations in line A were the highest among the concentrations in the three lines (i.e., lines $\mathrm{A}$, $\mathrm{B}$, and $\mathrm{C}$ ). The TPH concentrations from sites A3, B3 and C3 were the highest in each corresponding line, as shown in Fig. 2. The TPH concentration was highest in the site near the leak point and gradually decreased along the coastline, both in parallel and perpendicular directions from the leak point. According to the standard pollution levels in bottom sediments (Massoud et al. 1996), the sediments from sites $\mathrm{B} 2, \mathrm{C} 1, \mathrm{C} 2$, and MED were slightly polluted. The other sites (except for Shilaoren Beach) were moderately polluted. The high concentration found at site MED means oil pollution occurred; slower degradation and weathering rates may have caused oil to accumulate at this site.

\section{The characteristics of petroleum hydrocarbons in sediments}

The n-alkane was analysed by the GC-MS method. Samples from nine sites in Jiaozhou Bay were tested. The total alkane concentrations ranged from 157.92 to $373.48 \mu \mathrm{g} / \mathrm{g}$. Sites A3, B3 and C3 also contained the highest concentrations in each of their corresponding lines. This was consisted with the distribution of TPH concentrations. The concentrations of alkanes in samples A2, B2, C1 and C2 


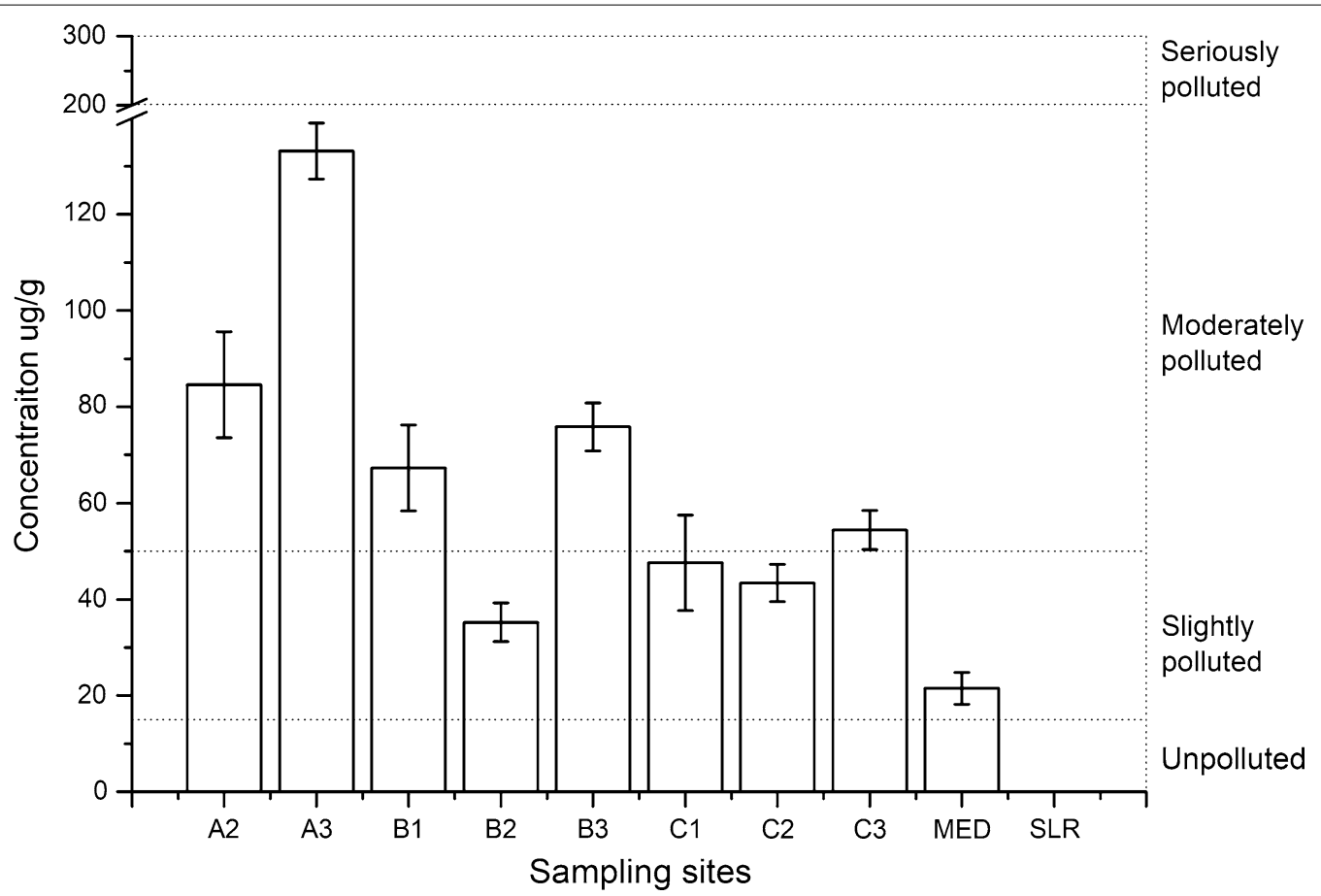

Fig. 2 The total petroleum hydrocarbons in sampling sediment analysis by fluorescence spectrophotometry. The concentrations of the TPHs were calculated by the standard curve. The site A3 was next to the leak point. No TPH was detected at site SLR. The symbol An (Bn, Cn): the nst sampling site of line A (B, C); MED: control site in Jiaozhou Bay; SLR: control site in Shilaoren Beach, which was outside of Jiaozhou Bay

were close to the alkane concentration at the control site MED, while concentrations at the other sites were much higher. In Fig. 3, the abundance of short-chain alkanes (C9-C20) were similar in sites A3, B3, and C3. The most abundant types of carbon in the three sites were middlechain alkanes (C21-C26). The alkanes with more than 31 carbon atoms were not as abundant. The abundance of each alkane at site MED was quite different from those of

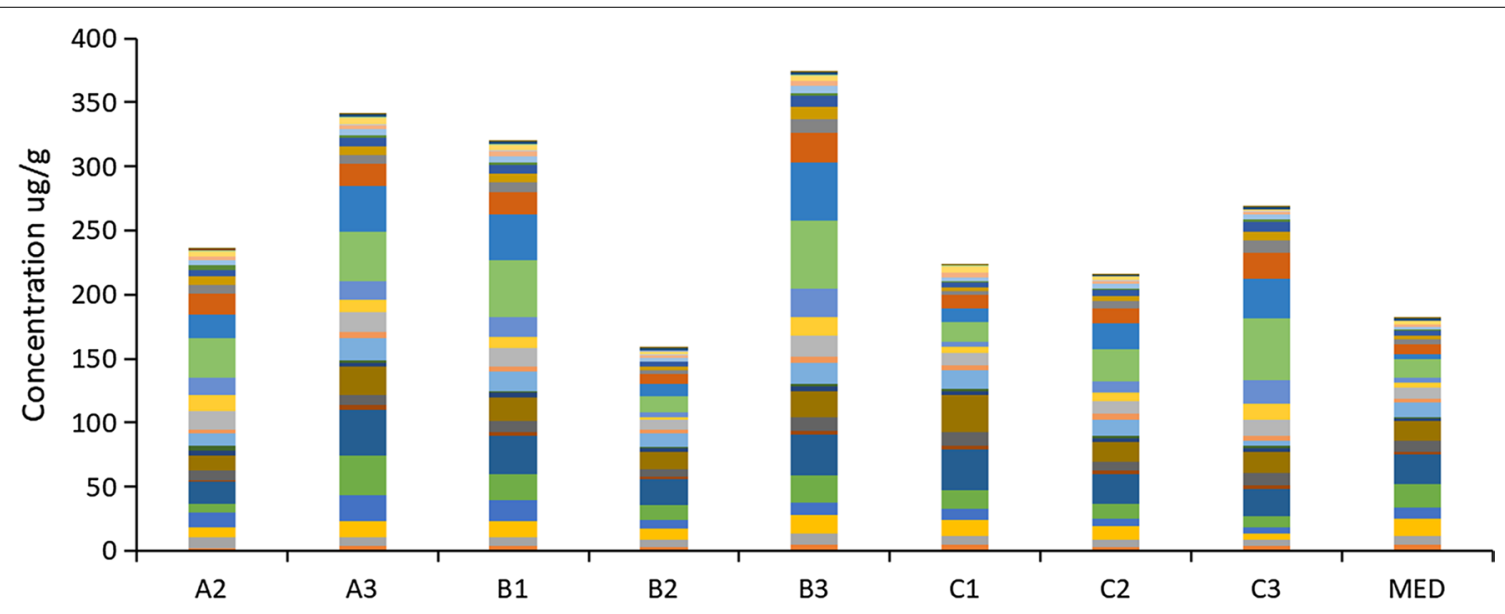

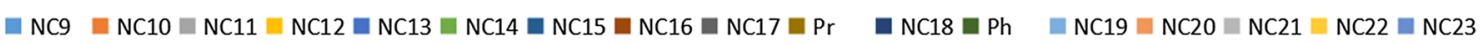

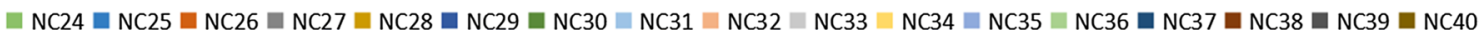

Fig. 3 The abundance of $n$-alkanes in sampling sediment analysis by GC-MS. The symbol An (Bn, Cn): the nst sampling site of line A (B, C); MED: control site in Jiaozhou Bay; SLR: control site in Shilaoren Beach, which was outside of Jiaozhou Bay. Internal standards were determined using n-tetracosane-D50 $(10 \mu \mathrm{g} / \mathrm{mL})$. The abundance of each $\mathrm{n}$-alkane was calculated by the internal standards 
the three sites (i.e., A3, B3 and C3); specifically, the abundance of C22-C31 alkanes were much higher in the three sites than in the control site MED.

The distributions of PAHs were quite different from the distributions of $\mathrm{n}$-alkanes in the sediments. The abundance of PAHs in site A3 $(38.7 \mu \mathrm{g} / \mathrm{g})$ was the highest of all surveyed sites. The concentration in other sites ranged from 6.4 to $17.5 \mu \mathrm{g} / \mathrm{g}$. The control site MED was also polluted with PAHs, with a concentration of $14.04 \mu \mathrm{g} / \mathrm{g}$. The concentration of PAHs in line A was the highest among the three lines (i.e., line A, line B and line C). This was similar to the distributions of $\mathrm{n}$-alkanes. The concentrations of PAHs in lines B and C were similar to the control site. The characteristics of the PAHs were analysed by GC-MS. NAPs was the main component in all the sites (shown in Fig. 4). The sediment samples from site A3 contained the highest concentrations of NAPs and were $52.7-74.9 \%$ higher than the control site MED. The concentrations of NAPs in the control site were $64.3-165.0 \%$ higher than the concentrations in site C3 (excluding C4-NAP), and site B3 was similar to the control site. This means that site MED in Jiaozhou Bay was contaminated by PAHs to some extent.

\section{Distribution and diversity of microbial communities in sediments}

The sites A3, B3 and C3, which had higher oil concentrations, were chosen for the study of microbial diversities; in contrast, sites MED and SLR served as control sites (Fig. 5). In all sites, Proteobacteria was the main phylum, accounting for $51.97-62.28 \%$ of the community. All the sites contained a certain degree of Thaumarchaeota, which was different than reports from former studies (e.g., King et al. 2015; Rivers et al. 2013). When comparing the seriously contaminated site (A3) and the other four sites, we found that the abundances of Actinobacteria and Acidobacteria were much lower at site A3. The abundance of Bacteroidetes at site A3 was higher than the abundances at the other three sites (except site SLR). There was also a considerably high abundance of Bacteroidetes at site SLR, and this was close to the abundance of the same phylum at site A3. What is interesting is the distribution of the phylum Tenericutes. The phylum Tenericutes showed a high abundance at site A3 (4.17\%). In addition, the compositions of Tenericutes at the other four sites were much lower $(<0.1 \%)$. Thus, Tenericutes was studied as apparent bacteria found in oil-contaminated areas, which meant that the community at site A3 was still affected by the spilled oil.

The genera found at the greatest abundances in the five sites were studied by cluster analysis, shown as a heatmap in Fig. 6. The diversity at site A3 was completely different from the diversity at the other four sites. The main genera at site A3 were oil-degrading or PAH-degrading bacteria, such as Alcanivorax and Lutibacter. The community at site SLR also presented a distinct structure compared with the genera of the other four sites. The results of principal component analysis (PCA) indicated that bacteria at sites A3, B3, and SLR were represented by three types of communities (Additional file 1: Figure S1). The communities at sites C3 and MED indicated a high similarity in community structure at the genus level. In

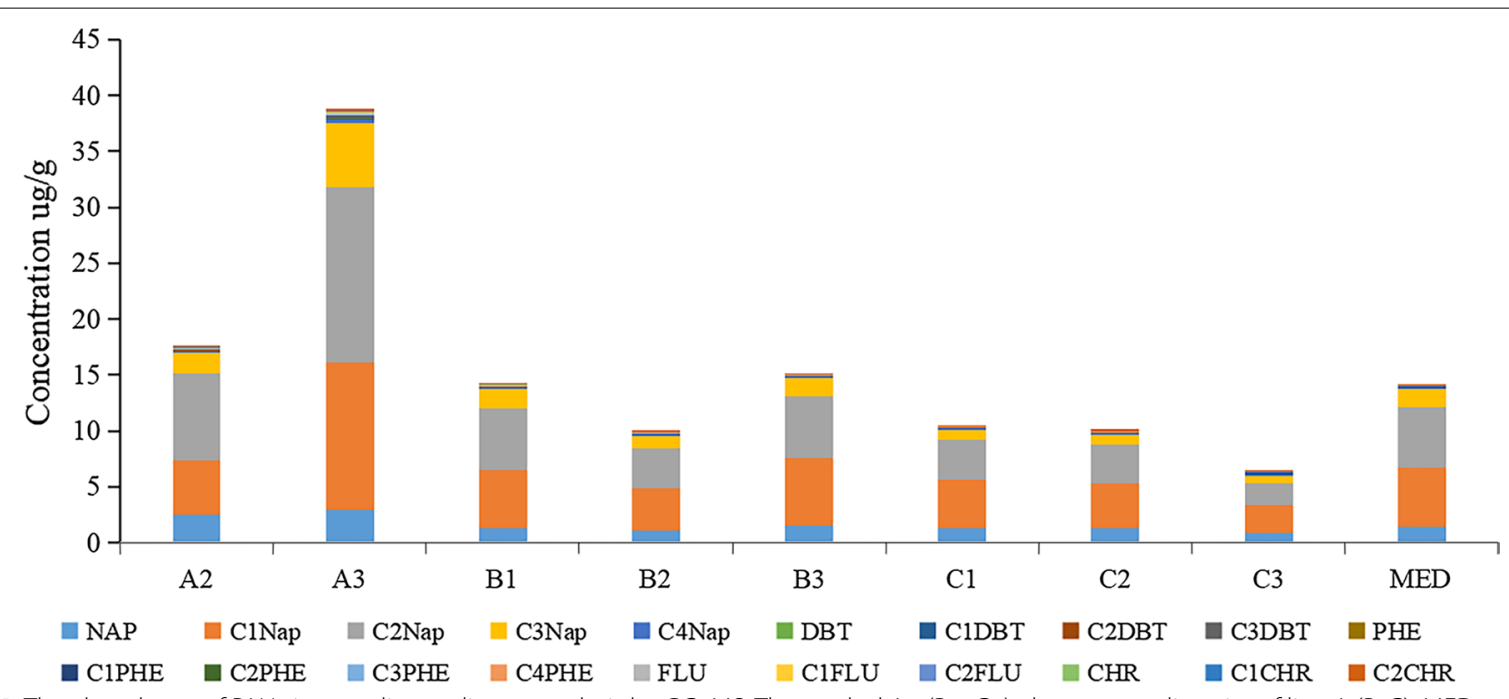

Fig. 4 The abundance of PAHs in sampling sediment analysis by GC-MS. The symbol $A n$ (Bn, $C n$ ): the nst sampling site of line $A(B, C)$; MED: control site in Jiaozhou Bay; SLR: control site in Shilaoren Beach, which was outside of Jiaozhou Bay. Internal standards were determined using $p$-terphenylD14 $(10 \mu \mathrm{g} / \mathrm{mL})$. The abundance of each PAH was calculated by the internal standards 


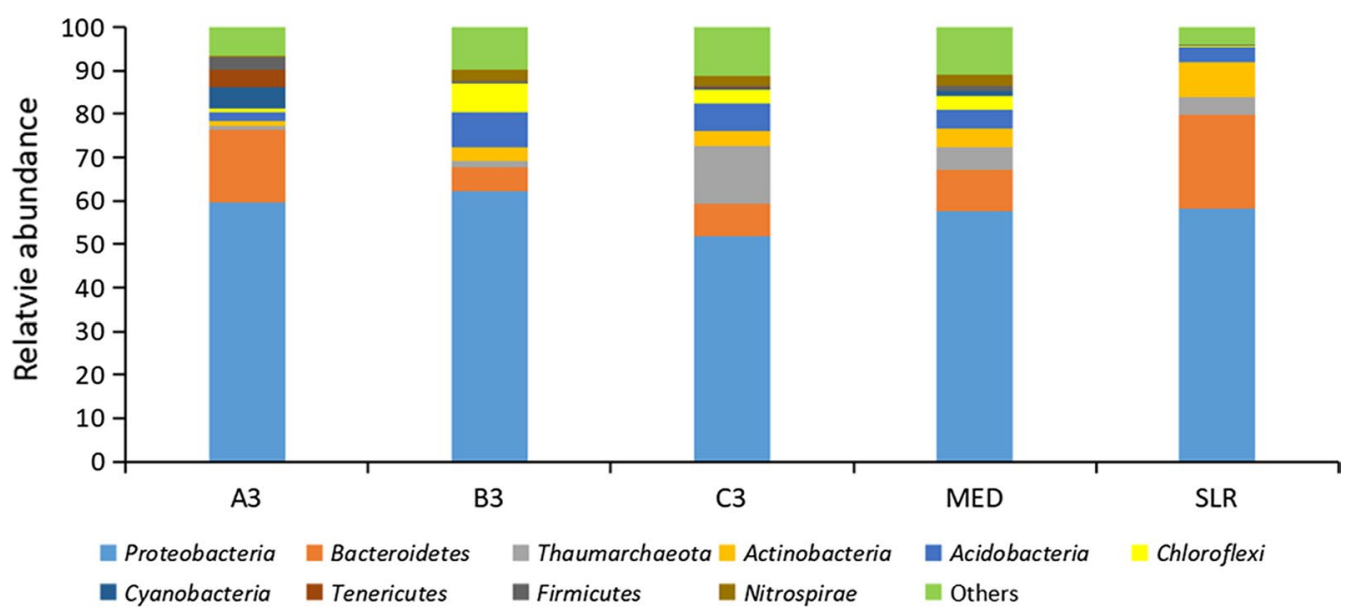

Fig. 5 The bacterial biodiversity in the sediments in the direction perpendicular to the shoreline. The map was generated from the highest abundance of the top 10 species at the phylum level. The symbol A3 (B3, C3): the sampling site near the leak point; MED: control site in Jiaozhou Bay; SLR: control site outside of Jiaozhou Bay

addition, the concentration of total petroleum hydrocarbon at site A3 was the highest, and it gradually decreased from $\mathrm{B} 3$ to $\mathrm{C} 3$; additionally, the communities at these sites were distinguished (clustered) following the distribution of pollutants. This was also demonstrated by the PCA results (Additional file 1: Figure S1).

\section{The biotoxicity of sediments with different levels of pollution}

The biotoxicity of sites A3, B3, C3, MED and SLR was evaluated by the luminescent bacteria method. The biotoxicity was presented as the equivalent concentration of $\mathrm{HgCl}_{2}$, which was calculated by the standard curve (Additional file 1: Figure S2). The sediment with the highest toxicity was collected from site $\mathrm{A} 3$, where the equivalent concentration of $\mathrm{HgCl}_{2}$ was $0.04 \mathrm{mg} / \mathrm{L}$. The equivalent concentrations in the sediments from sites $\mathrm{C} 3$ and SLR were very low, no more than $0.01 \mathrm{mg} / \mathrm{L}$ (Fig. 7). To simplify the results of our data, toxicity was divided into three levels: a: no toxicity with an equivalent concentration below zero; b: low toxicity with an equivalent concentration $\leq 0.02 \mathrm{mg} / \mathrm{L}$; and c: moderate toxicity with an equivalent concentration $>0.02$ and $\leq 0.1 \mathrm{mg} / \mathrm{L}$. Sediment from site SLR exhibited no toxicity; samples from site C3 showed low toxicity; and sediments from sites A3, B3 and MED exhibited moderate toxicity.

\section{Discussion}

Offshore oil well blowouts or pipeline ruptures cause large amounts of oil to spill into marine environments, such as the Deepwater Horizon oil spill, the Bohai 19-3 oil spill and the Huangdao 11.22 oil pipeline explosion. Oil dispersants were widely applied in the marine oil removal process (Kleindienst et al. 2015). The dispersants lower the oil-water interfacial tension and break oil slicks into fine droplets. These dispersed oils may aggregate with suspended particulate material (SPM), such as clay minerals or organic matter, to form oil-SPM aggregates (OSAs) that get trapped on the bottom substrates in nearshore waters (Gong et al. 2014). It was estimated that $65 \%$ of released oil might form OSAs. This may result in serious pollution to the benthic environment because of the large amount of the spilled oil associated with each event. Studies have shown that oil including relatively labile low-molecular-weight n-alkanes, aromatics and BTEX (benzene, toluene, ethylbenzene, and $p$-, $m$-, and $o$-xylenes) remained in sediments 1 year after a spill (Liu et al. 2012). In our study, TPH was detected in all sediments from the nine sampling sites in Jiaozhou Bay. Five of the nine sites were moderately polluted according to Massoud's et al. standard (1996). The TPH concentration of site A3 (near the oil leaking point) was close to a heavily polluted value (i.e., $>200 \mu \mathrm{g} / \mathrm{g}$ ). In a previous study of Jiaozhou Bay, the concentrations of PAHs ranged from 1242.21 to $29,558.13 \mathrm{ng} / \mathrm{g}$ in sediments (Xue 2009). In the present study, the concentrations of PAHs were within this range at most sites. However, the concentration at site A3 was much higher than the average value found in Jiaozhou Bay. This means there was an exogenous input of PAHs to this site. On the other hand, the previous studies showed that the PAHs were mainly composed of high-molecular-weight components. In our study, low-ring PAHs accounted for a large proportion. Another study in Daya Bay showed that the increase in naphthalene content may be due to oil pollution, and this supports that the contamination of the sediments in Jiaozhou Bay was from crude oil (Sun et al. 2016). 


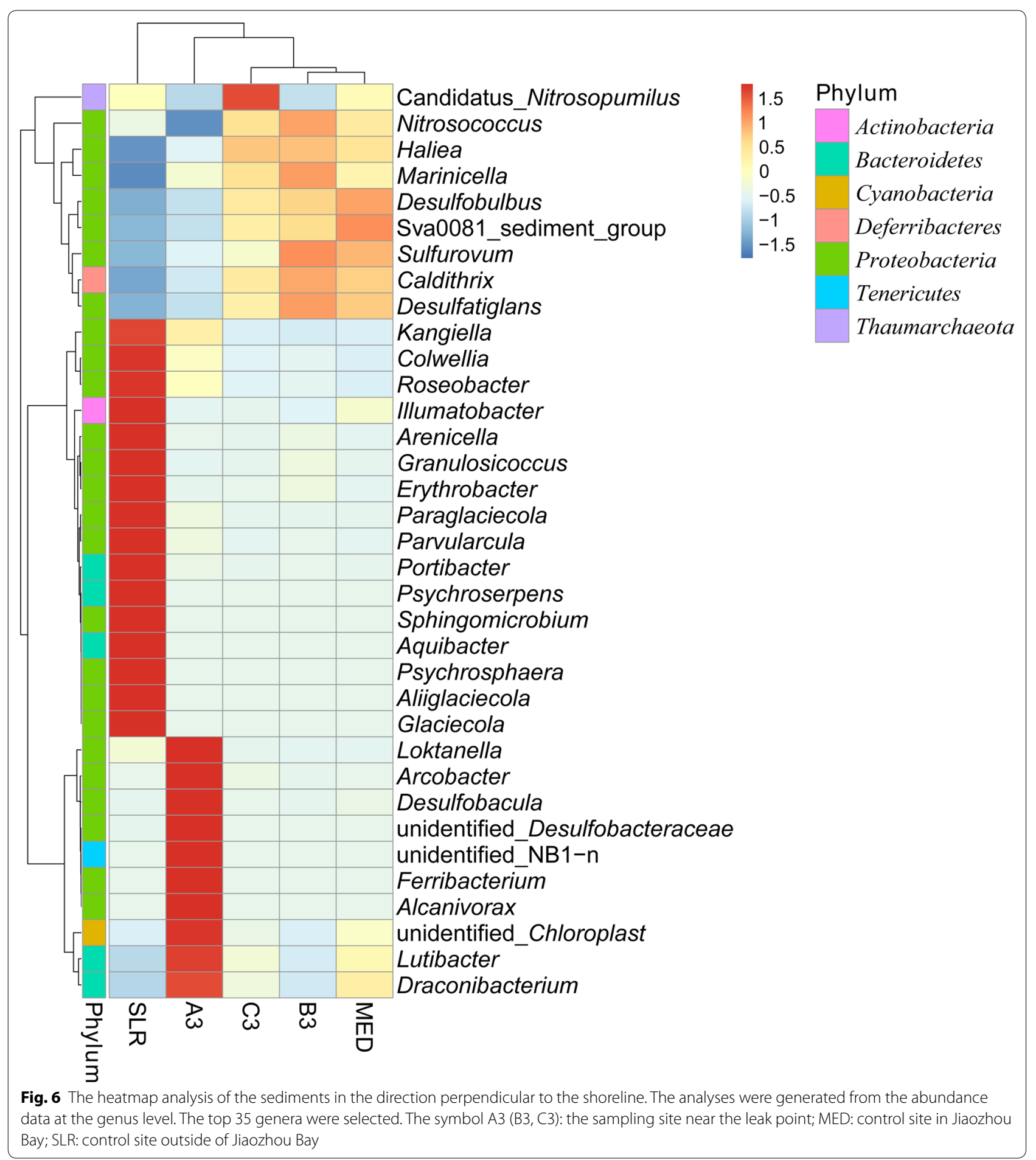

The quick responses and succession of microbial communities in seawater or beach sediments were frequently studied after an oil spill (Hazen et al. 2010; Mason et al. 2012; Redmond and Valentine 2012). However, the impacts of the spilled oil on a sedimentary ecosystem after years of contamination have been less studied. Due to the low weathering effect, the oil might have a much longer impact time on the bacterial community. In our study, the bacterial communities at the five sites vertically distributed along the shoreline were considerably 


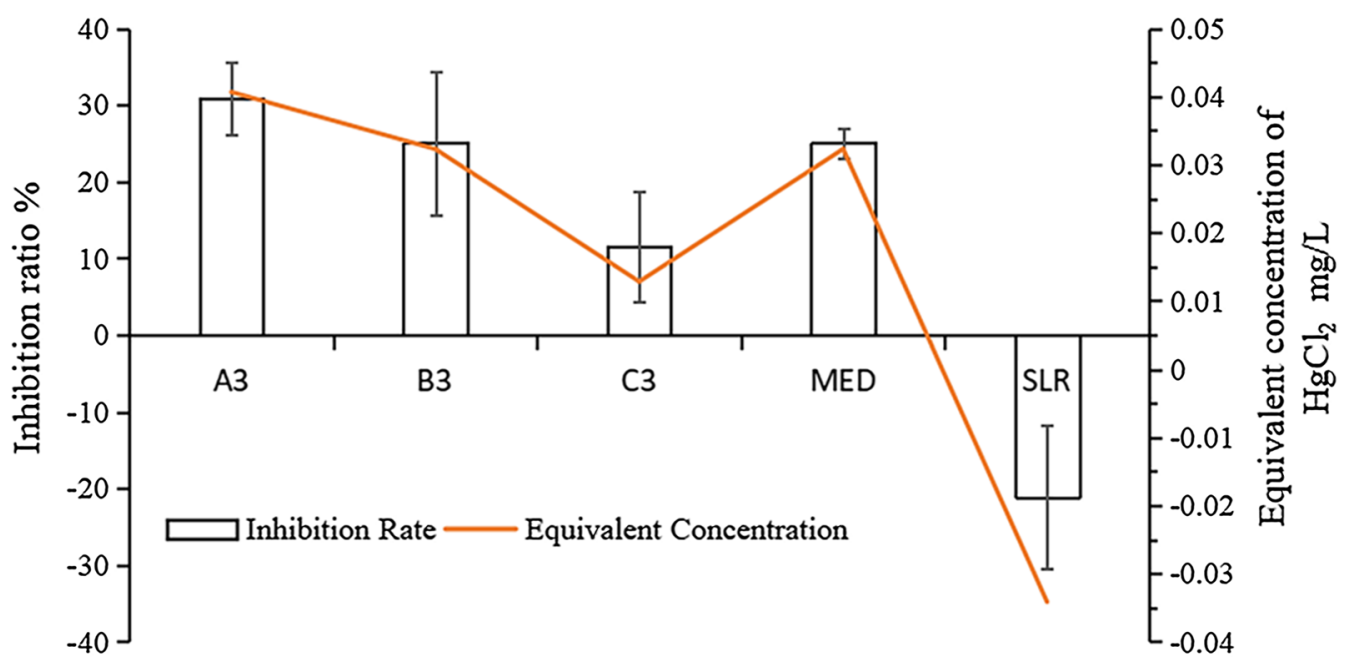

Fig. 7 The luminous inhibition ratio and the equivalent concentration of $\mathrm{HgCl}_{2}$ in different sediments. The inhibition rates and equivalent concentrations of $\mathrm{HgCl}_{2}$ were shown in the figure. The inhibition rates were calculated by the negative control. The equivalent concentrations of $\mathrm{HgCl}_{2}$ were calculated according to the standard curve. The symbol A3 (B3, C3): the sampling site near the leak point; MED: control site in Jiaozhou Bay; SLR: control site outside of Jiaozhou Bay

different. The bacterial communities were dominated by oil-degrading bacteria in seriously polluted sites. The abundance of Firmicutes, Tenericutes and Cyanobacteria accounted for $11.58 \%$ of the community at site A3, and species in these phyla were connected to oil contamination in marine environments (Ding et al. 2015; Ichor et al. 2016; Liu et al. 2012). Cyanobacteria showed high oil-degrading abilities and was considered to have good application potential in oil clean-up efforts (Raghukumar et al. 2001). Firmicutes were known to degrade hydrocarbons and were representative of the oil contamination at site A3. Additionally, they were the dominant phylum found in oil mousses (Liu and Liu 2013). Koo et al. (2015) found Firmicutes were a late responder after the oil contamination but had not been detected in the control. Tenericutes were also a late abundant phylum studied by Ding et al. (2015). Additionally, these two phyla were the main strains in the oil-polluted site A3, which meant that the oil pollution in the marine sediments at site A3 might last for years. The bacterial communities at the five sites were clustered by genera data. Site A3, with the highest concentrations of TPH and PAHs, was dominated by oildegrading bacteria, such as Lutibacter and Alcanivorax, which was significantly different from the communities of the slightly polluted area and the non-polluted area. Thus, the results of the bacterial cluster could reflect the degree of oil pollution in sediments. When comparing between the moderately polluted and the non-polluted areas, Erythrobacter showed a big difference. From the studies of the Deepwater Horizon spill, Erythrobacter was the dominant genus in the oil mousses (Liu and Liu
2013). However, in this study, it was also one of the dominant genera found in the non-contaminated site SLR. The Erythrobacter spp. belonged to the aerobic anoxygenic phototrophic bacteria, which play a critical role in the carbon cycle in the ocean and these bacteria could metabolise organic substrates (Kolber et al. 2001; Yurkov and Beatty 1998). Why was the genus Erythrobacter more abundant in the clean area than in the polluted area? This might be because Erythrobacter spp. grow well in environments with high levels of organic matter content, such as oil or other types. The presence of Erythrobacter as dominant bacteria at the control site was probably due to the abundance of other forms of organic substrates.

In summary, the oil content in the water and along the coast quickly decreased because of the usage of dispersants and the weathering effect. In contrast, the oil in benthic sediments was more stable and difficult to degrade. Therefore, the spilled oil in sediments caused long-term impacts on the microbial community. We studied the oil polluted sites and two non-polluted control sites. The results showed that the microbial community abundance was consistent with the oil contamination which was supported by heatmap and PCA results. The sediments from seriously polluted, moderately polluted, slightly polluted, and non-polluted sites exhibited different microbial communities and biotoxicities. These differences to a certain extent could be used to evaluate the level of oil pollution in marine sediments. Understanding the impacts of spilled oil on indigenous microbial communities and identification of oil-degrading microbial 
groups were prerequisites for the clean-up efforts of oilcontaminated marine benthic ecosystems.

\section{Additional file}

Additional file 1: Figure S1. PCA results of the sampling sediments.

Figure S2. The standard curve of the biotoxicity analysis.

\section{Abbreviations}

TPH: total petroleum hydrocarbons; PAHs: polycyclic aromatic hydrocarbons; CTAB: cetyltrimethyl ammonium bromide; SDS: sodium dodecyl sulphate; OTUs: operational taxonomic units; SPM: suspended particulate material; OSAs: oil-SPM aggregates; PCA: principal component analysis.

\section{Authors' contributions}

WG and $X Y$ designed the whole experiment and contributed equally to the paper, and TM worked on project design and article revisions. YZ, FL and BH helped with the analyses of TPH, alkane and PAHs. XL helped complete the paperwork. The biotoxicity analysis was done by $X Z$ under the direction of ZC. WG wrote the article, and LZ provided instruction on the experimental design and helped with article revisions. All authors read and approved the final manuscript.

\begin{abstract}
Author details
${ }^{1}$ College of Marine Life Sciences, Ocean University of China, Qingdao 266003, China. ${ }^{2}$ Key Laboratory for Marine Bioactive Substances and Modern Analytical Technology, The First Institute of Oceanography, State Oceanic Administration of China, No. 6 Xianxialing Road, Qingdao 266000, Shandong, People's Republic of China. ${ }^{3}$ College of Environmental Science and Engineering, Ocean University of China, Qingdao 266100, China. ${ }^{4}$ Key Laboratory of Marine Chemical Theory and Technology, Ministry of Education, Qingdao 266100, China. ${ }^{5}$ Laboratory for Marine Ecology and Environmental Science, Qingdao National Laboratory for Marine Science and Technology, Qingdao 266071, China.
\end{abstract}

\section{Acknowledgements}

We thank Changfei He, Guangfei Xu and Bing Wang for the sediment sampling in this work.

\section{Competing interests}

The authors declare that they have no competing interests.

\section{Availability of data and materials}

All datasets from which the conclusions of the manuscript rely were presented in the main paper. All sequencing data were submitted to the GenBank Sequence Read Archive, and the BioProject accession number is PRJNA399274.

\section{Consent for publication \\ Not applicable.}

Ethics approval and consent to participate

Not applicable.

\section{Funding}

This work was supported by the National Natural Science Foundation of China (41406127, 41476103); The National Natural Science Foundation of ChinaShandong Joint-Funded Project (U1606404); China-ASEAN Maritime Cooperation Fund East Asia Marine Cooperation Platform and the Marine Science and Technology Project of Huangdao District (2014-4-20).

\section{Publisher's Note}

Springer Nature remains neutral with regard to jurisdictional claims in published maps and institutional affiliations.

Received: 30 January 2018 Accepted: 25 April 2018

Published online: 09 May 2018

\section{References}

Acosta-González A, Rosselló-Móra R, Marqués S (2013) Characterization of the anaerobic microbial community in oil-polluted subtidal sediments: aromatic biodegradation potential after the Prestige oil spill. Environ Microbiol 15(1):77-92

Beyer J, Trannum HC, Bakke T, Hodson PV, Collier TK (2016) Environmental effects of the Deepwater Horizon oil spill: a review. Mar Pollut Bull 110(1):28-51

Bokulich NA, Subramanian S, Faith JJ, Gevers D, Gordon Jl, Knight R, Mills DA, Caporaso JG (2013) Quality-filtering vastly improves diversity estimates from Illumina amplicon sequencing. Nat Methods 10(1):57-59

Caporaso JG, Kuczynski J, Stombaugh J, Bittinger K, Bushman FD, Costello EK, Fierer N, Peña AG, Goodrich JK, Gordon JI (2010) QIIME allows analysis of high-throughput community sequencing data. Nat Methods 7(5):335-336

DeSantis TZ, Hugenholtz P, Larsen N, Rojas M, Brodie EL, Keller K, Huber T, Dalevi D, Hu P, Andersen GL (2006) Greengenes, a chimera-checked $16 \mathrm{~S}$ rRNA gene database and workbench compatible with ARB. Appl Environ Microbiol 72(7):5069-5072

Ding C, Ma T, Hu A, Dai L, He Q, Cheng L, Zhang H (2015) Enrichment and characterization of a psychrotolerant consortium degrading crude oil alkanes under methanogenic conditions. Microb Ecol 70(2):433-444

Edgar RC (2004) MUSCLE: multiple sequence alignment with high accuracy and high throughput. Nucleic Acids Res 32(5):1792-1797

Edgar RC (2013) UPARSE: highly accurate OTU sequences from microbial amplicon reads. Nat Methods 10(10):996-998

Edgar RC, Haas BJ, Clemente JC, Quince C, Knight R (2011) UCHIME improves sensitivity and speed of chimera detection. Bioinformatics 27(16):2194-2200

Gao X, Gao W, Cui Z, Han B, Yang P, Sun C, Zheng L (2015) Biodiversity and degradation potential of oil-degrading bacteria isolated from deep-sea sediments of South Mid-Atlantic Ridge. Mar Pollut Bull 97(1):373-380

Gong Y, Zhao X, O'Reilly S, Qian T, Zhao D (2014) Effects of oil dispersant and oil on sorption and desorption of phenanthrene with Gulf Coast marine sediments. Environ Pollut 185:240-249

Haas BJ, Gevers D, Earl AM, Feldgarden M, Ward DV, Giannoukos G, Ciulla D, Tabbaa D, Highlander SK, Sodergren E (2011) Chimeric 16 S rRNA sequence formation and detection in Sanger and 454-pyrosequenced PCR amplicons. Genome Res 21(3):494-504

Hazen TC, Dubinsky EA, DeSantis TZ, Andersen GL, Piceno YM, Singh N, Jansson JK, Probst A, Borglin SE, Fortney JL (2010) Deep-sea oil plume enriches indigenous oil-degrading bacteria. Science 330(6001):204-208

Hong S, Khim JS, Ryu J, Park J, Song SJ, Kwon BO, Choi K, Ji K, Seo J, Lee S (2012) Two Years after the Hebei spirit oil spill: residual crude-derived hydrocarbons and potential AhR-mediated activities in coastal sediments. Environ Sci Technol 46(3):1406-1414

Ichor T, Okerentugb PO, Okpokwasil GC (2016) Biodegradation of total petroleum hydrocarbon by a consortium of Cyanobacteria isolated from crude oil polluted brackish waters of bodo creeks in Ogoniland, Rivers State. Res J Environ Toxicol 10(1):16-27

King GM, Kostka JE, Hazen TC, Sobecky PA (2015) Microbial responses to the deepwater horizon oil spill: from coastal wetlands to the deep Sea. Ann Rev Mar Sci 7(1):377-401

Kleindienst S, Paul JH, Joye SB (2015) Using dispersants after oil spills: impacts on the composition and activity of microbial communities. Nat Rev Microbiol 13(6):388-396

Kolber ZS, Gerald F, Plumley, Lang AS, Beatty JT, Blankenship RE, Vandover CL, Vetriani C, Koblizek M, Rathgeber C (2001) Contribution of aerobic photoheterotrophic bacteria to the carbon cycle in the ocean. Science 292(5526):2492-2495

Koo H, Mojib N, Huang JP, Donahoe RJ, Bej AK (2015) Bacterial community shift in the coastal Gulf of Mexico salt-marsh sediment microcosm in vitro following exposure to the Mississippi Canyon Block 252 oil (MC252). 3. Biotech 5(4):379-392

Liu Z, Liu J (2013) Evaluating bacterial community structures in oil collected from the sea surface and sediment in the northern Gulf of Mexico after the Deepwater Horizon oil spill. Microbiologyopen 2(3):492-504

Liu Z, Liu J, Zhu Q, Wu W (2012) The weathering of oil after the Deepwater Horizon oil spill: insights from the chemical composition of the oil from the sea surface, salt marshes and sediments. Environ Res Lett 7(3):035302 
Luan X (2015) Study on rapid detection method of biotoxicity of seawater samples using luminescent bacterium Acinetobacter spTox2 and Acinetobacter sp. RecA. Dissertation, First Institute of Oceanography SOA

Magoč T, Salzberg SL (2011) FLASH: fast length adjustment of short reads to improve genome assemblies. Bioinformatics 27(21):2957-2963

Mason OU, Hazen TC, Borglin S, Chain PS, Dubinsky EA, Fortney JL, Han J, Holman HY, Hultman J, Lamendella R, Mackelprang R, Malfatti S, Tom LM, Tringe SG, Woyke T, Zhou J, Rubin EM, Jansson JK (2012) Metagenome, metatranscriptome and single-cell sequencing reveal microbial response to Deepwater Horizon oil spill. ISME J 6(9):1715-1727

Massoud M, Al-Abdali F, Al-Ghadban A, Al-Sarawi M (1996) Bottom sediments of the Arabian Gulf-II TPH and TOC contents as indicators of oil pollution and implications for the effect and fate of the Kuwait oil slick. Environ Pollut 93(3):271-284

Peterson CH, Rice SD, Short JW, Esler D, Bodkin JL, Ballachey BE, Irons DB (2003) Long-term ecosystem response to the exxon valdez oil spill. Science 302(5653):2082-2086

Raghukumar C, Vipparty V, David J, Chandramohan D (2001) Degradation of crude oil by marine Cyanobacteria. Appl Microbiol Biotechnol 57(3):433-436

Redmond MC, Valentine DL (2012) Natural gas and temperature structured a microbial community response to the Deepwater Horizon oil spill. Proc. Nat. Acad. Sci. 109(50):20292-20297

Rivers AR, Sharma S, Tringe SG, Martin J, Joye SB, Moran MA (2013) Transcriptional response of bathypelagic marine bacterioplankton to the Deepwater Horizon oil spill. The ISME Journal 7(12):2315-2329

Rochelle PA (ed) (2001) Environmental molecular microbiology: protocols and applications Horizon. Scientific Press
Romero IC, Toro-Farmer G, Diercks AR, Schwing P, Muller-Karger F, Murawski S, Hollander DJ (2017) Large-scale deposition of weathered oil in the Gulf of Mexico following a deep-water oil spill. Environ Pollut 228(C):179-189

Sun RX, Lin Q, Ke CL, Du FY, Gu YG, Cao K, Luo XJ, Mai BX (2016) Polycyclic aromatic hydrocarbons in surface sediments and marine organisms from the Daya Bay, South China. Mar Pollut Bull 103(1-2):325-332

Wang Q, Garrity GM, Tiedje JM, Cole JR (2007) Naive Bayesian classifier for rapid assignment of rRNA sequences into the new bacterial taxonomy. Appl Environ Microbiol 73(16):5261-5267

White HK, Lyons SL, Harrison SJ, Findley DM, Liu Y, Kujawinski EB (2014) Longterm persistence of dispersants following the Deepwater Horizon oil spill. Environ Sci Technol lett 1(7):295-299

Xu GF (2016) Standardization and application of luminescent bacteria test in the biotoxicity detection of marine pollutants. Dissertation, Qingdao university of science and technology

Xue LD (2009) Source apportionment of PAHs in coastal surface sediments from Jiaozhou Bay and Rizhao offshore area. Dissertation, Ocean University of China

Yergeau E, Maynard C, Sanschagrin S, Champagne J, Juck D, Lee K, Greer CW (2015) Microbial community composition, functions, and activities in the gulf of mexico 1 year after the Deepwater Horizon accident. Appl Environ Microbiol 81(17):5855-5866

Yurkov W, Beatty JT (1998) Aerobic anoxygenic phototrophic bacteria. Microbiol Mol Biol Rev 62(3):695-724

Zheng L, Cui Z, Gao W, Han B, Yang B, Wang S, Li Q, Zhou W, Zhang K, Cao L (2012) Field study of bioremedation of oil-contaminated Dalian beach by marine oil-degrading bacterial agent. Acta Oceanolog Sin 34:163-172

\section{Submit your manuscript to a SpringerOpen ${ }^{\circ}$ journal and benefit from:}

- Convenient online submission

Rigorous peer review

- Open access: articles freely available online

- High visibility within the field

Retaining the copyright to your article

Submit your next manuscript at springeropen.com 